Acta Cryst. (2002). A58 (Supplement), C45

\section{SYNCHROTRON WHITE BEAM X-RAY TOPOGRAPHY AND HIGH \\ RESOLUTION TRIPLE AXIS X-RAY DIFFRACTION STUDIES OF DEFECTS IN SiC SUBSTRATES, EPILAYERS AND DEVICE STRUCTURES}

M. Dudley

State University of New York At Stony Brook Materials Science \& Engineering SUNY At Stony Brook STONY BROOK NY 11794-2275 USA

A general review will be presented of recent synchrotron white beam x-ray topography (swbxt) studies of defects in SiC single crystals carried out at Stony Brook and at the Stony Brook Synchrotron Topography Station at the National Synchrotron Light Source, Brookhaven National Laboratory. Results will be presented from studies of (a) $4 \mathrm{~h}$ and $6 \mathrm{~h} \mathrm{SiC}$ substrates growth by physical vapor transport, (b) homoepitaxial layers grown on such substrates, (c) hetereoepitaxial layers grown on $4 \mathrm{~h}$ substrates, and (d) sic device structures Swbxt results will be correlated with those from afm, Nomarski optical microscopy, high resolution triple-axis x-ray diffraction (hrtxd), sem and tem studies carried out on the same crystals. From (a), substrate defects observed include closed-core and hollow-core screw dislocations (micropipes) in 6h and $4 \mathrm{~h}$, deformation-induced basal plane dislocations in $6 \mathrm{~h}$ and $4 \mathrm{~h}$; and small angle boundaries in $4 \mathrm{~h}$. The possible origins for these defects will be discussed. Studies investigating the relationship between micropipe hollow-core diameter and the burgers vector will also be outlined, including the techniques used for burgers vector determination. From (b) results from studies of the correlation between substrate and epilayer defects in $6 \mathrm{~h} / 6 \mathrm{~h}$ homoepitaxial layers will be presented. From (c) polytype mapping in $3 \mathrm{c} / 4 \mathrm{~h}$ sic heterostructures will be described. The relationship between substrate and epilayer defects will again be explored as will the lattice mismatch between epilayer and substrate as indicated by a combination of swbxt and hrtxd. In (d) examples of research exploring the influence of defects on device performance will be presented.

Keywords: X-RAY TOPOGRAPHY, DEFECTS, SILICON CARBIDE CRYSTALS, DISLOCATIONS, MICROPIPES

Acta Cryst. (2002). A58 (Supplement), C45

$X$-RAY INVESTIGATION OF A(III)-B(V) SEMICONDUCTORS IMPLANTED WITH HIGH DOSES OF IONS

W. K. Wierzchowski ${ }^{1}$ K. Wieteska ${ }^{2}$ W. Graeff ${ }^{3}$ A. Turos ${ }^{1,5}$ G. Gawlik ${ }^{1}$ R. Groetzschel $^{4}$

${ }^{1}$ Institute of Electronic Materials Technology, Warsaw ,Poland ${ }^{2}$ Institute of Atomic Energy, Otwock-Swierk, Poland ${ }^{3}$ HASYLAB at DESY, Hamburg, Germany ${ }^{4}$ Rossendorf Research Centre, Germany ${ }^{5}$ Soltan Institute for Nuclear Problems, Warsaw, Poland

$\mathrm{Al}_{\mathrm{x}} \mathrm{Ga}_{1-\mathrm{x}} \mathrm{As}, \quad \mathrm{In}_{\mathrm{x}} \mathrm{Ga}_{1-\mathrm{x}} \mathrm{As}_{1-\mathrm{y}} \mathrm{P}_{\mathrm{y}}$ and $\mathrm{GaAs}$ implanted at room and higher temperatures with high doses of $\mathrm{MeV} \mathrm{Se}, \mathrm{As}, \mathrm{Si}$ as well as $100-170 \mathrm{keV} \mathrm{H}^{+}$ and $\mathrm{He}^{+}$ions were studied with synchrotron X-ray diffraction methods: white beam section and projection topography, rocking curve measurement, reciprocal space mapping and plane wave topography. The examination was performed both as implanted and for selected samples after thermal annealing cycles. Small dislocation density of the samples enabled observation of many diffraction phenomena. The simulation of rocking curves and other diffraction patterns was used for determination of the strain distribution. Part of the samples was annealed up to $300^{\circ} \mathrm{C}$.

The implantation to $\mathrm{Al}_{\mathrm{x}} \mathrm{Ga}_{1-\mathrm{x}} \mathrm{As}$ at room temperature did not cause lattice amorphisation even for $1 \times 10^{16} \mathrm{~cm}^{-2}$ of $1.5 \mathrm{MeV}$ Se. In case of these ions for doses higher than $1 \times 10^{15} \mathrm{~cm}^{-2}$ the strain profile was dominated by a component directly connected with distribution of introduced selenium atoms. The strain profiles for implantation with $\mathrm{H}^{+}$and $\mathrm{He}^{+}$were well approximated by distribution of introduced point defects. A characteristic phenomenon observed after annealing of $\mathrm{H}^{+}$ion implanted samples was sharpening of the strain maximum in the mostly deformed layer. For longer annealing the vanishing of interference effects was observed due to strain irregularities preceding the exfoliation.

The studies were performed both with the reciprocal space mapping and pinhole topography exhibited only moderate increase of diffuse scattering in the case of highest selenium doses and annealed proton implanted samples.

Keywords: A(III)B(V) SEMICONDUCTORS IMPLANTATION X-RAY STUDIES
Acta Cryst. (2002). A58 (Supplement), C45

X-RAY OBSERVATION OF LARGE-DIAMETER CZ-SILICON BY A 300-mm-WIDE MONOCHROMATIC BEAM

$\underline{\text { S. Kawado }}^{1}$ S. Iida $^{2}$ Y. Chikaura ${ }^{3}$ M. Umeno ${ }^{4}$

${ }^{1}$ Rigaku Corporation X-Ray Research Laboratory 3-9-12 Matsubara-Cho, Akishima-Shi TOKYO 196-8666 JAPAN ${ }^{2}$ Faculty of Science, Toyama University ${ }^{3}$ Faculty of Engineering, Kyushu Institute of Technology ${ }^{4}$ Graduate School of Engineering, Osaka University

We created an experimental apparatus designed to acquire large-area topographs of silicon crystals at beamline bl20b2 in the spring- 8 . This setup uses a horizontally $300-\mathrm{mm}$-wide monochromatic X-ray beam realized by the $200 \mathrm{~mm}$ distance between the experimental hutch and the bending-magnet source. One-shot exposure for topograph could cover the whole surface of a 10 mm-thick $300 \mathrm{~mm}(001)$ Czochralski (cz) silicon crystal by using asymmetric 115 and 2212 reflections of 21 and $60 \mathrm{kev} x$-rays, respectively, and it revealed saw marks caused by slicing and minute residual damage caused by polishing. In addition, this technique has also succeeded in clarifying the difference in surface-strain distribution caused by various steps of 200-mm (001) cz silicon wafer manufacturing. The sliced and lapped wafers gave a topographic image over the whole surface with one shot exposure because of poor crystallinity, while the etched, ground and polished wafers required step scanning of omegarotation, owing to the existence of warp in spite of good crystallinity in local areas. We conclude that the $300 \mathrm{~mm}$-wide monochromatic $\mathrm{x}$-ray beam is useful for measuring the warp of large-diameter silicon wafers from the stepscanned topographs as well as inspecting surface damage such as saw marks and microscratches.

\section{Keywords: X-RAY TOPOGRAPHY SILICON SURFACE STRAIN}

Acta Cryst. (2002). A58 (Supplement), C45

STRUCTURAL RELATIONSHIP IN HIGH PRESSURE ELEMENTAL SOLIDS

J.S. Tse D.D. Klug H. Tutuncu

National Research Council of Canada Steacie Institute For Molecular Sciences 100 Sussex Drive Ottawa Ontario K1a 0R6 CANADA

Recent experimental studies has revealed many complex structures in elemental solids under high pressure. Some of the structure-types are new and not observed in normal materials. In an attempt to rationalize possible underlying common structural principles for these structures, high pressure phase transitions in several elemental solids have been characterized with firstprinciples electronic and phonon calculations. We explore the relationship between structures and the nature of chemical bonding and demonstrate there is a natural connection between successive high pressure phases. We also investigate the role of electron-phonon coupling in high pressure structures to their possible superconductivity.

Keywords: HIGH PRESSURE STRUCTURES 